\title{
PENSAR E AGIR EM CENA COM ADOLESCENTES EM ESCOLAS PÚBLICAS
}

Thinking and scratching with adolescents in public schools

Pensar y actuar en escena con adolescentes en escuelas públicas
Elen Alves dos Santos - Centro Universitário do Planalto Central Apparecido dos Santos / Universidade de Brasília - Brasília- DF/Brasil
Lúcia Helena Cavasin Zabotto Pulino - Universidade de Brasília

Elen Alves dos Santos

Psicóloga

Mestre em Educação

Doutoranda em Psicologia (PGPDS) pela Universidade de Brasília. Docente no Ensino Superior UNICEPLAC - Centro Universitário do Planalto Central Apparecido dos Santos

\section{Lúcia Helena Cavasin Zabotto Pulino \\ Psicóloga (USP) \\ Doutora em Filosofia (UNICAMP) \\ Pós-doutorado (Université PARIS 8)}

Professora Adjunta no Instituto de Psicologia da Universidade de Brasília. Brasília-DF/Brasil

\begin{tabular}{c} 
Correspondência \\
Elen Alves dos Santos \\
SIGA Área Especial para Indústria Lote 2/3, Sce St. Leste Industrial - Gama, Brasília - DF, Brasil. \\
CEP: 72445-020 \\
Telefone: 55 (61) 999243148 \\
E-mail: $\underline{\text { elenpsi@gmail.com }}$ \\
\hline
\end{tabular}




\title{
Resumo
}

Esse artigo apresenta um relato de experiência profissional. Primeiramente, propõe uma articulação teórica entre adolescência, ressentimento e subjetivação política. Segue-se o relato de uma estratégia de intervenção nomeada "pensar e agir em cena" realizada com adolescentes no ambiente escolar, com o objetivo de criar um espaço/tempo de promoção de subjetivação política. Os resultados da experiência permitem que se acompanhe e análise o processo de subjetivação política e acendem a necessidade de novas intervenções nas escolas públicas que permitam a construção de espaços que promovam a subjetivação política de adolescentes. Conclui-se que atividades como essas são fundamentais para o adolescente ter um espaço de fala e de deslocamentos subjetivos para que se construam proposições coletivas.

Palavras-chave: adolescência; ressentimento; subjetivação política; psicanálise

\begin{abstract}
This article presents an account of professional experience. First, it proposes a theoretical articulation between adolescence, resentment and political subjectivation. This is followed by the report of an intervention strategy named "think and act on the scene" carried out with adolescents in the school environment, aiming at creating a space / time to promote political subjectivation. The results of the experience make possible to follow and analyse the process of political subjectivation and raise the need for new interventions in public schools that allow the construction of spaces of political subjectivation for adolescents. It is concluded that activities like these are fundamental for the adolescent to have a space of speech, of subjective displacements for collective propositions.
\end{abstract}

Keywords: adolescence; resentment; political subjectivation; psychoanalysis. 


\section{Resumen}

Este artículo presenta un relato de experiencia profesional. Primero, propone una articulación teórica entre adolescencia, resentimiento y subjetivación política. A continuación, presenta el relato de una estrategia de intervención denominada "pensar y actuar en escena" realizada con adolescentes en el ambiente escolar, con el objetivo de crear un espacio / tiempo de promoción de subjetivación política. Los resultados de la experiencia permiten que se siga el proceso de subjectivación y suscitan la necesidad de nuevas intervenciones en las escuelas públicas que permitan la construcción de espacios de subjetivación política para adolescentes. Se concluye que actividades como éstas son fundamentales para el adolescente tener un espacio de habla, de desplazamientos subjetivos para proposiciones colectivas.

Palabras clave: adolescencia; resentimiento; subjetivación política; psicoanálisis. 


\section{Introdução}

Este relato de experiência profissional assume a adolescência como uma construção social, própria da sociedade ocidental organizada ao final do século XIX, condizente com a extensão da infância; e com a inserção escolar, conforme assevera Phillipe Ariés (2011). Discorrer sobre adolescência implica necessariamente, analisar o contexto da Modernidade, que traz em seu bojo uma apologia ao individualismo, a busca pelo hedonismo, e uma intensa valorização ao status de ser jovem. E propaga o ideal de que cada sujeito é responsável pela sua manutenção e direcionamento por um lugar social, sem um senso de coletividade (Corso \& Corso, 2018; Coutinho, 2015; Calligaris, 2010; Birman, 2006).

Em uma perspectiva psicanalítica, entende-se que a adolescência é um trabalho psíquico, que decorre das elaborações infantis e das exigências pulsionais da puberdade, no contato com o mundo social. Entende-se que quanto mais caótica estiver a organização cultural e social, maiores conflitos os adolescentes vivenciarão na tentativa de ocupar um lugar para si. Na contemporaneidade, percebe-se que o lugar do outro social que conceda suporte ao adolescente está cada vez mais ausente (De Oliveira \& Hanke, 2017).

A leitura de Donald Winnicott $(1964 ; 2005)$, psicanalista inglês, aponta para a necessidade de entender a adolescência em face da sociedade. Seu enfoque epistemológico ao ambiente, isto é, ao espaço de acolhimento, de suporte físico e psíquico, que inicialmente é a mãe, porém depois estende-se aos ambientes externos, reitera que “crescer" não depende apenas das tendências herdadas, mas da organização do ambiente, seja a família, a escola e a sociedade. Questiona-se se os ambientes ofertados aos adolescentes na atualidade são suficientemente bons.

A adolescência é esse momento em que o outro social terá um sentido equivalente ao que os pais tiveram na infância (Corso \& Corso, 2018). Alguns autores sinalizam que a 
adolescência carece de referências sociais que lhe dêem o direcionamento para uma atividade simbólica (Coutinho, 2009; Calligaris, 2010).

Diante do exposto, e com base na obra de Maria Rita Kehl (2007), "Ressentimento", indaga-se se a sociedade contemporânea não estaria propiciando aos adolescentes caminhos para o ressentimento. Segundo a autora, o ressentimento é um termo do senso comum, entendido como a dificuldade de esquecer ou perdoar. Na compreensão do texto, o ressentido funciona da seguinte forma:

1. O ressentido, pode se posicionar sob as formas de vítima, revestir-se de uma moralidade, encher-se de razões para colocar-se queixoso, ao invés de assumir o movimento de reivindicar e lutar.

2. A queixa do ressentido é indireta, mostra desejo de vingança, essa que ele não age para que ocorra, pois existe um gozo em sua queixa, que se mostra pela via da repetição.

3. O ressentido abre mão de seu desejo para um outro que considera superior, e depois exige insistentemente um retorno do que abriu mão.

4. Por fim, uma das questões principais do ressentimento é que "o sujeito estabeleça uma relação de dependência infantil com o outro supostamente poderoso, a quem caberia protegê-lo, premiar seus esforços, e reconhecer seu valor” (Kehl, 2007, p. 14).

Essa proposta de articular a adolescência a um momento de ressentimento traz como eixo central problematizar a adolescência como uma construção social e cultural, que dispõe os adolescentes a um momento de latência/espera social. Para Kehl (2007) os ressentidos vivem sob uma promessa de igualdade e de democracia de direitos, percebida como uma “dádiva paterna dos poderosos", em que eles se colocam na espera para obterem de seus superiores o que lhes fora prometido. 
Essas promessas feitas aos adolescentes podem se configurar como reais e simbólicas, que condizem com as expressões comumente ditas aos jovens, como "quando crescer você poderá fazer"; "você é criança para isso, mas adulto para aquilo". Exige-se dos adolescentes ora uma postura de responsabilidade, ora outra de infantilidade perante si mesmo e a sociedade. A psicanalista Françoise Dolto (2015) discute que na ausência de ritos de passagem, os adolescentes tendem a ficar entregues a si mesmos em busca de atividades que muitas vezes resultam em ações de risco.

Haja vista, a existência de crises no mundo e no cenário brasileiro, o adolescente vive uma crise mergulhado em outra crise (De Oliveira \& Hanke, 2017). Crise que se acentua sobretudo para os adolescentes pelo próprio momento de reelaboração psíquica, e pelo fato de os espaços sociais estarem interditados a eles: a rua, as quadras esportivas, algumas escolas tomadas pela violência, sofrem de um mal-estar (crise), principalmente adolescentes e jovens da periferia, que se percebem cada vez mais imersos nas incertezas de ocuparem um lugar social (Birman, 2006).

$\mathrm{Na}$ falta dessas possibilidades, o adolescente pode vivenciar a fase de forma "queixosa", no isolamento de suas demandas, na falta de reconhecer que seus conflitos podem ser semelhantes aos de seus pares (Winnicott, 1964; Corso \& Corso, 2018). Nessa perspectiva, pressupõe-se que a sociedade ocidental e contemporânea suscita à adolescência o ressentimento.

Em face dessa explanação teórica entende-se a necessidade de conceder ao sujeito adolescente um espaço de palavra, em cumprimento inclusive do que trata o artigo 16, do Estatuto da Criança e do Adolescente (1990), nos incisos 2, 5 e 6: direito a opinar, a participar da vida familiar, comunitária e da política. Analisa-se a subjetivação política como uma 
forma de possibilitar um lugar de participação efetiva aos adolescentes, conforme apresentado na seção seguinte.

\section{Subjetivação política na adolescência}

O termo subjetivação política é constituído a partir das ideias do filósofo francês Jacques Rancière (1995). Para o autor, a subjetivação política é a elaboração coletiva que ocorre pelo reconhecimento de estar entre identidades, que sejam construídas no coletivo e não cristalizadas e dadas como uma identidade pronta. No Brasil, Castro e Matos (2009) sustentam que a noção de subjetivação política se articula com a adolescência, sobretudo nos contextos escolares. A subjetivação política acena para uma demanda subjetiva alinhada às questões sociais, por se deslocar do pessoal, individual e ser alçada ao coletivo.

Infere-se, a partir de trabalhos realizados com adolescentes, que a falta de uma proposta que vise uma subjetivação política induz os adolescentes para alguns caminhos como: 1. Alienação em relação ao que é falado e discutido no campo social; 2. Distanciamento do processo educacional. 3. Isolamento familiar e social 3. Abertura para condutas de risco (autoagressão e heteroagressão). 5. Dificuldade de construção de uma autonomia, e de corresponsabilizar-se (Jucá \& Vorcaro, 2019; Santos \& Legnani, 2019; Corso \& Corso, 2018; Santos, 2016).

O processo de subjetivação política caracteriza-se pela oportunidade de tornar-se coletiva uma experiência, que é queixa comum a todos, em ações que criam um senso de coletividade, de pertencimento, responsabilidade perante o outro (Rabello de Castro, 2016). A subjetivação política com adolescentes pode ocorrer de diferentes formas, Rabello de Castro (2016) por exemplo, apresenta relatos de subjetivação política realizada no interior das escolas públicas, no exercício do grêmio estudantil, associações estudantis e trabalhos 
voluntários. É uma ação que possibilita aos adolescentes vivenciarem a adolescência de modo não ressentido, mas engajado socialmente nos diferentes grupos.

\section{Metodologia}

Trata-se de um relato de experiência profissional a partir de estratégias de intervenção, por meio da oficina Pensar e agir em cena ${ }^{1}$. Esta se constrói na perspectiva de que subjetivar-se politicamente é também possibilitar a circulação da fala, de ideias e de ações, de forma crítica e reflexiva. Essa oficina originou-se a partir da solicitação de de estudantes, membros do grêmio estudantil de uma escola pública de Ensino Médio, de uma palestra sobre suicídio de adolescentes, após ter ocorrido um caso na escola.

Propôs-se que, ao invés de uma palestra, o trabalho consistiria em atividades de encenação teatral. Partiu-se do pressuposto de que a encenação teatral mobiliza o que é muito crítico na adolescência, o corpo e o agir impulsivo. A oficina também se embasou na ideia do Teatro do Oprimido (Boal, 2010), em que o teatro é por si só, um ato político, por serem as ações humanas políticas. Baseou-se na ideia de que o corpo em cena possibilita catarse e associação livre (Santiago e Neves, 2008), e de técnicas do psicodrama, como a troca de atores e a interrupção da cena. A oficina teve como eixo de trabalho a possibilidade de que todos os participantes pudessem ser protagonistas, colocados em igualdade, possibilitando que o saber se construísse na troca de experiências.

\section{Procedimentos}

Em termos práticos, as oficinas ocorreram no auditório da escola, foram realizados quatro grupos compostos por 25 a 30 adolescentes. Os alunos que assistiam tinham a liberdade de interromper a cena e sugerir novas ações, à medida que considerassem

1. A oficina foi inclusa como projeto de extensão do Centro Universitário do Planalto Central Aparecido dos Santos -Uniceplac/ Gama-DF. 
necessário. Ao final de cada cena, abria-se um diálogo coletivo sobre a história escolhida e as resoluções propostas. Aproveitou-se do potencial criativo dos alunos, das angústias e experiências vivenciadas, de forma que pudessem pensar e refletir coletivamente sobre situações de vida, sobre os conflitos e as possíveis estratégias de resolução.

\section{Resultados e discussão}

Conforme apresentado, foram organizados quatro grandes grupos para a realização dessa atividade, cujos temas eleitos foram: Entrevista de trabalho (como conseguir um trabalho quando se exige experiência e ninguém concede ao jovem a oportunidade; abuso moral no espaço da escola; uso de drogas; dificuldades das famílias em aceitarem a orientação sexual dos filhos adolescentes. Devido à extensão do relato, apresenta-se aqui apenas o tema sobre a entrevista de trabalho.

O grupo desenvolveu uma cena em que uma adolescente de 18 anos em uma entrevista, apresentou dificuldades para conseguir o trabalho, por não ter experiência prévia. As falas suscitaram: "é difícil conseguir um trabalho, pois exigem experiências e nós não temos"; “ eu nem tento mais, porque todos me dizem não", "estágio é para poucos”. Segundo Corso e Corso (2018), em atividades que incorporem o perceber, intervir, fazer e pensar, desenvolvidas com e pelos adolescentes, há maiores possibilidades de os jovens terem suporte para lidar com as questões da adolescência, rompendo com a latência social.

De início, alguns adolescentes se mostraram bastante ressentidos (Kehl, 2007), culpabilizando o Estado e o Governo pela falta de oportunidade, com dificuldades de se perceberem como sujeitos de direitos e deveres, que podem e devem ter voz no campo educativo e social (Rabello de Castro, 2016). Depois, os diálogos que surgiram eram em torno de ações que os adolescentes podem desenvolver para romper com a descrença e com a falta do senso de oportunidades, como a reivindicação por mais estágio, trabalhos 
voluntários com certificações, solicitação de apoio de instituições como Sesc, Sebrae, voltadas para treinamento e aperfeiçoamento profissional, dentre outros.

Ao final, os adolescentes reconheceram que não pensavam nessas saídas e ao término do Ensino Médio, se sentiam desesperançosos sobre o contexto de mercado de trabalho; algo muito comum, no cenário de jovens da periferia brasileira (Birman, 2006). É nesse interstício que ocorre a subjetivação política, no deslocamento subjetivo para o encontro com o outro, que apresenta demandas semelhantes. Ao mesmo tempo em que os adolescentes se queixaram da falta de oportunidades, também se implicaram em seus questionamentos, trazendo para si responsabilidades.

\section{Considerações finais}

A subjetivação política rompe com a noção de que uns são aptos e outros não a serem sujeitos políticos e dá condições para que esta seja uma discussão coletiva, possibilitando aos jovens uma postura menos ressentida. Evidencia-se que as participações de adolescentes brasileiros em ações políticas são fundamentais para a produção de sentimentos de pertencimento às instituições coletivas e para a sua responsabilização frente às questões comuns da sociedade. Em outras palavras, é um exercício coletivo que ajuda no trabalho psíquico característico da adolescência.

O relato de atuação profissional em Psicologia aqui apresentado, embora de maneira bastante sucinta, evidencia as possibilidades de trabalho que podem ser pensadas em coletivos de adolescentes. Como uma fase de novas identificações, a adolescência pode ser um momento de formação de grupo, tanto para caminhos de subjetivação política, como para a entrega ao ressentimento.

Entende-se que o objetivo da oficina Pensar e Agir em Cena foi alcançado, na medida em que foi criado um espaço/tempo de promoção de subjetivação política, mostrando que 
atividades como essa, de expressão corporal e verbal, podem vir a ser suporte aos adolescentes, frente à ausência de ritos de passagem que os direcionem (Dolto, 2018), pois trabalham no campo do que é coletivo, e favorecem um anteparo social ao adolescente.

\section{Referências}

Ariés, P. (1981). História social da criança e da família. Rio de Janeiro: Zahar.

Birman, J. (2006). Tatuando o desamparo: a juventude na atualidade. Adolescentes.

Calligaris, C. A. (2010). Adolescência. Publifolha, São Paulo.

Castro, L. R. De; Mattos, A. R. (2009). O que é que a política tem a ver com a transformação de si: Considerações sobre a acção política a partir da juventude. Anál. Social, n.193.

Corso, D. L., \& Corso, M. (2018). Adolescência em cartaz: filmes e psicanálise para entendê-la. Artmed Editora.

Coutinho, L. G. (2015). O adolescente e a educação no contemporâneo: o que a psicanálise tem a dizer. Cadernos de psicanálise (Rio de Janeiro), 37(33), 155-174.

De Oliveira, H. M., \& Hanke, B. C. (2017). Adolescer na contemporaneidade: uma crise dentro da crise. Ágora: Estudos em Teoria Psicanalítica, 20(2), 295-310.

Dolto, F. (2015). A causa dos adolescentes/Françoise Dolto; tradutor Orlando Reis.

Jucá; V \&Vorcaro, A.M.R. (2019). Escarificações na adolescência: tentativas de de reinscrição do sujeito por meio de cortes. In: Chatelard \& Maesso ( Orgs). O corpo no discurso psicanalítico. (pp. 81-94) Curitiba: Appris.

Kehl, M. R. (2007). Ressentimento. Casa do Psicólogo.

Lei $N^{o} 8.069$, de 13 de julho de 1990. Dispõe sobre o estatuto da criança e do adolescente e dá outras providências. Diário Oficial União, 16 jul. 1990.

Rabello de Castro, L. (2016). Subjetividades públicas juvenis: a construção do comum e os impasses de sua realização. Estudos de Psicologia, 21 (1), 80-91. 
Rancière, J. (1995). Politics, Identification and Subjectivization. In: Rajchman, J. (ed.). The Identity in Question. London: Routledge.

Santos, E. A. dos, \& Legnani, V. N. (2019). Construção Social do Fracasso Escolar das Adolescentes em Conflito com a Lei. Psicologia: Ciência e Profissão, 39, e180302. Epub 14 de mar o de 2019.https://dx.doi.org/10.1590/1982-3703003180302

Santos, E. A. dos. (2016). As adolescentes em cumprimento de medida socioeducativa: um diálogo sobre as questões de gênero, escolarização, sociedade de consumo e ato infracional. (Dissertação de Mestrado). Universidade de Brasília, Brasília, Brasil. Recuperado de: http://dx.doi.org/10.26512/2016.02.D.22693

Winnicott, D. W. (1964). A juventude não dormirá. In: Privação e delinqüência. São Paulo: Martins Fontes.

Winnicott, D. W., \& Sandler, P. (2005). Tudo começa em casa. $4^{\mathrm{a}}$ ed. - São Paulo: Martins Fontes.

Submissão: 8 de dezembro de 2018

Última revisão: 17 junho de 2019

Aceite final: 30 de junho de 2019 